\title{
Outcome of Needle Fenestration, Subacromial Steroid and Diclofenac Phonophoresis in Acute Calcific Tendinitis of Shoulder
}

\author{
Rajendra Sanjel Chhetri, ${ }^{1}$ Kishor Prashad Khatri, ${ }^{2}$ Jagadish Khanal,, Milan KC' \\ 'Department of Orthopedics, Lumbini Zonal Hospital and Lumbini Hospital and Technical College, Butwal, Nepal.
}

\section{ABSTRACT}

Introduction: Acute calcific tendinitis of shoulder is very painful and disturbing condition. There are many modalities with variable outcome to address the condition. We studied needling technique with multiple fenestration, subacromial steroid and diclofenac phonophoresis and evaluated the outcome in term of pain relief and improvement of shoulder function at a simple outpatient clinical set up without image or ultrasound guidance.

Methods: We studied cases of acute calcific tendinitis presenting within one week from onset of symptoms and X-ray showing calcific deposit. All underwent needle fenestration at maximum tender site with lignocaine loaded syringe, subsequent injection of $40 \mathrm{mg}$ subacromial methylprednisolone and diclofenac phonophoresis done by qualified physiotherapist for five days. Visual Analogue Scale was used to measure pain, Simple shoulder Test applied to evaluate shoulder function and size of calcific deposit was measured at maximum length.

Results: Pain subsided dramatically and there was substantial improvement of shoulder function within a week.

Conclusions: Needle fenestration and subacromial methylprednisolone along with diclofenac phonophoresis without image guidance gives excellent pain reduction and improves shoulder function which can be done at simple outpatient clinic.

Keywords: acute calcific tendinitis; phonophoresis; simple shoulder test; visual analogue scale.

\section{INTRODUCTION}

Acute calcific tendinitis commonly affecting supraspinatus tendon is quite dramatic with sudden onset of severe pain, exquisite tenderness and attempted motion is very painful. ${ }^{1,2}$ Tenocytes response to exposed mechanical force undergo metaplasia into chondrocyte like cell and subsequently deposit basic calcium phosphate. ${ }^{3}$

Several treatment options has been proposed but clinical results are controversial and often remain a matter of clinician's choice. ${ }^{4}$ Ultrasound enhances drug delivery by increasing cell permeability and also increases diffusion hence phonophoresis is more effective than topical application of gel. ${ }^{5-8}$ Needle aspiration or barottage is painful and may need general anesthesia furthermore localization of the deposit warrants image guidance and is often used in many studies for needling and aspiration with variable outcome..$^{9,10}$

Hence purpose of our study is to evaluate the outcome of needle fenestration at maximum tender point without image guidance, subacromial steroid and diclofenac

Correspondence: Dr. Rajendra Sanjel Chhetri, Department of Orthopedics, Lumbini Zonal Hospital, Butwal, Nepal. Email: sanjelr@ gmail.com, Phone: +977-9857028329. 
phonophoresis at outpatient clinic to evaluate the effectiveness in term of pain relief and functional outcome.

\section{METHODS}

This observational study was conducted at Lumbini Zonal Hospital and Lumbini Hospital and Technical College, Butwal, Nepal from August 2011 to July 2017. Patients visiting outpatient clinic with onset of shoulder pain within one week with visible calcific deposit on X-ray were included in our study. Ethical approval was taken from the Institutional Review Committee. Those visiting more than one week of onset of symptoms or shoulder pain without X-ray evidence of calcific deposit were excluded. Duration of symptoms was one to seven days (average 3.5 days). Treatment procedure was explained to all and consent was taken. Visual Analogue Scale (VAS) was used to score the level of pain due to its simplicity, reliability and validity as well as its ratio scale properties. ${ }^{11,13}$ A vertical VAS of $100 \mathrm{~mm}$ was used ranging across a continuum from no pain zero to extreme pain 100. Function of shoulder was scored and recorded with modified Simple Shoulder Test (SST), scored zero for "no" answer and score one for "yes" answer. ${ }^{14}$ Size of the calcific deposit was measured on its maximum length.

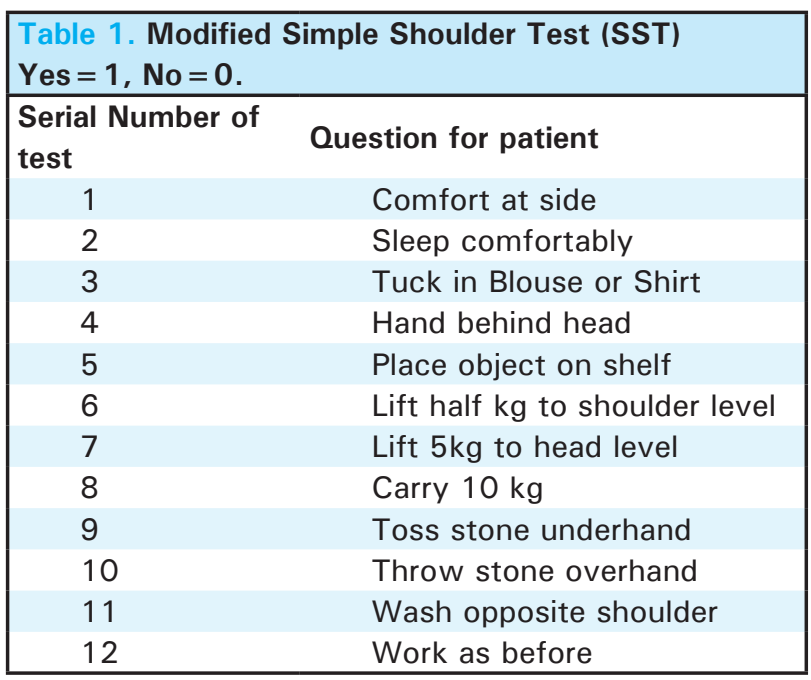

We used diclofenac diethyl ammonium $1.6 \% \mathrm{w} / \mathrm{w}$ equivalent to diclofenac sodium $1 \% \mathrm{w} / \mathrm{w}$ gel with Meditech brand ultrasound machine (made in India) with one megahertz probe for five minutes in continuous mode to deliver the drug by phonophoresis, done once a day for minimum of five days. Two $\mathrm{ml}$ of $2 \%$ lignocaine in $10 \mathrm{ml}$ disposable syringe with $21 \mathrm{G}$ needle was used to blindly puncture the deposit multiple times marked as maximum tender site, injecting the local anesthetic during the fenestration. We avoided large bore needle and aspiration to minimize pain during procedure.
Finally needle advanced to subacromial space using different syringe preloaded with methyl prednisolone $40 \mathrm{mg}$ and $2 \%$ lignocaine. All patients were given oral indomethacin $25 \mathrm{mg}$ thrice a day for five days and were asked to follow up in one week, one month, one year and later. Our average follows up was 11.7 months (range 1-49months).

VAS, SST score and size of the deposit were noted. Data collected and analyzed using standard statistical test including standard of deviation, paired t test to test the hypothesis of no difference between initial VAS and VAS in one week, one week and one month and one month to final follow up. Hypothesis of no difference between initial SST and SST in one week, one month and one month and final follow up were tested using paired t test. Regression analysis was done to measure the correlation between initial size of deposit and VAS score.

\section{RESULTS}

In our study we found acute calcific tendinitis of shoulder commonly affecting elderly (average age 52.9 years), 14 (77.8\%) were females, 16 (88.9\%) gave some history of strain or overuse. Average duration of seeking treatment from onset of symptoms was 3.5 days (range 1-7days). Right side shoulder was involved in $15(83.3 \%)$. We had no simultaneous bilateral involvement but one of our patient had left shoulder involved three years later of right side.

All our patients initially presented to us had severe pain, mean VAS was 84.2 (Range 74-94). After continuous one megahertz diclofenac phonophoresis for five minutes for at least five days, multiple needle puncture at maximum tender site along with two $\mathrm{ml} 2 \%$ lignocaine and subacromial injection of $40 \mathrm{mg}$ methyl prednisolone mixed again with two $\mathrm{ml} 2 \%$ lignocaine, acute pain subsided in all within one week. Mean VAS in one week came down to 20.3 (range 7-37) showing significant decrease in pain (paired t test $P<0.001, S D$ 9.15).

Average initial Simple Shoulder Test (SST) score was 1.83 (range 0-3) in one-week SST score increased to 9.61 (range 8-10) showing significant improvement $(\mathrm{P}<0.001$ paired t-test, SD 1.003).

There was significant improvement of VAS from one week to one month $(P<0.001$ paired t-test, SD 3.84) and improvement from one month to final follow up (average final follow up 11.7 months) was nonsignificant ( $P>0.05$ paired t-test, SD 17.36) 


\begin{tabular}{|c|c|c|c|c|c|c|}
\hline $\begin{array}{l}\text { Case } \\
\text { No. }\end{array}$ & $\begin{array}{l}\text { Age } \\
\text { Sex }\end{array}$ & $\begin{array}{l}\text { Initial (Vas, } \\
\text { SST, Deposit } \\
\text { size in cm) }\end{array}$ & $\begin{array}{l}\text { One } \\
\text { week(VA, } \\
\text { SST, Deposit) }\end{array}$ & $\begin{array}{l}\text { One } \\
\text { month(VAS, } \\
\text { SST, Deposit) }\end{array}$ & $\begin{array}{l}\text { Final follow up } \\
\text { (VAS, SST, } \\
\text { Deposit) }\end{array}$ & $\begin{array}{l}\text { Duration of final follow } \\
\text { up(months) \& Remarks }\end{array}$ \\
\hline 1 & $60 \mathrm{M}$ & $87,2,2.2$ & $21,10,1.8$ & $12,11,1.2$ & $0,12,0.7$ & 10, pulled by cow \\
\hline 2 & $62 \mathrm{~F}$ & $92,0,1.5$ & $37,9,1.2$ & $20,10,0.8$ & $8,12,0.6$ & 11, dug field \\
\hline 3 & $37 \mathrm{M}$ & $78,3,0.75$ & $23,10,0.5$ & $13,11,0.3$ & $0,12,0$ & 13, chopped wood \\
\hline 4 & $53 F$ & $80,3,0.2$ & $14,10,0.1$ & $6,12,0$ & $5,12,0$ & 2, carried bucket \\
\hline 5 & $57 \mathrm{~F}$ & $93,0,1.4$ & $22,9,1.2$ & $11,11,0.8$ & $0,12,0$ & 49 , deweeded field \\
\hline 6 & $46 \mathrm{~F}$ & $93,0,0.6$ & $7,10,0.6$ & $4,12,0.3$ & $0,12,0.3$ & 4, no trauma \\
\hline 7 & $58 \mathrm{~F}$ & $81,2,0.8$ & $14,9,0.8$ & $7,11,0.8$ & $0,12,0.8$ & 12 , milked buffalo \\
\hline 8 & $49 F$ & $87,2,1.8$ & $16,10,1.4$ & $9,11,1.2$ & $0,12,0.8$ & 14, no trauma \\
\hline 9 & $65 \mathrm{M}$ & $76,3,0.2$ & $8,10,0.2$ & $6,12,0.2$ & $6,12,0.2$ & 1 , strained on scooty \\
\hline 10 & $55 \mathrm{~F}$ & $92,1,0.3$ & $22,10,0.3$ & $9,11,0.2$ & $6,12,0$ & 17, harvested paddy \\
\hline 11 & $27 F$ & $88,2,1.6$ & $34,9,1.4$ & $23,10,1.2$ & $68,2,0.8$ & $\begin{array}{l}13, \text { cut branches pain } \\
\text { recurred }\end{array}$ \\
\hline 12 & $49 F$ & $82,2,0.4$ & $20,10,0.3$ & $8,12,0.2$ & $8,12,0.2$ & $\begin{array}{l}1, \text { washed clothes at hand } \\
\text { pump }\end{array}$ \\
\hline 13 & $44 \mathrm{M}$ & $82,3,0.7$ & $13,10,0.6$ & $6,12,0.4$ & $0,12,0.2$ & 13, chopped wood \\
\hline 14 & $54 \mathrm{~F}$ & $78,3,1.7$ & $21,10,1.4$ & $9,11,1.2$ & $6,12,0.8$ & 5 , cut grass \\
\hline 15 & $72 \mathrm{~F}$ & $83,1,0.4$ & $36,8,0.4$ & $26,9,0.3$ & $72,8,0.2$ & 9, pain recurred on milking \\
\hline 16 & $55 \mathrm{~F}$ & $94,0,2.4$ & $23,9,2.0$ & $12,11,1.4$ & $0,12,0$ & 3, cut branches for cattle \\
\hline 17 & $53 F$ & $76,3,1.0$ & $14,10,0.8$ & $8,11,0.6$ & $0,12,0.3$ & 34, strained on raising up \\
\hline 18 & $56 \mathrm{~F}$ & $74,3,1.4$ & $21,10,1.2$ & $6,12,0.8$ & $6,12,0.8$ & 1, harvested maize \\
\hline
\end{tabular}

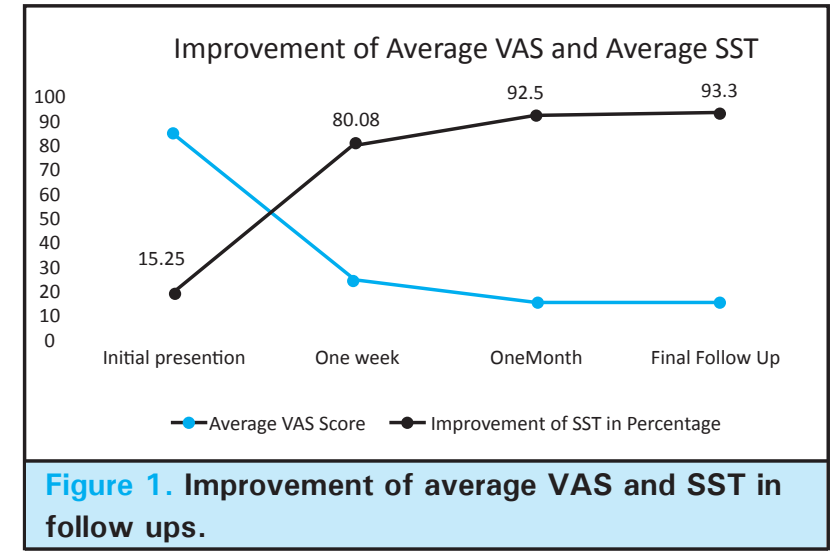

Increase in SST from one week to one month was significant $(P<0.001$ paired t-test, $S D 0.514)$ but long term result from one month to final follow up was nonsignificant ( $P>0.05$ paired t-test, SD 2.09).

Complete desolation of calcific deposit was seen in five $(27.8 \%)$, desolation by more than half in seven $(38.9 \%)$ and half or less than half desolation in six $(33.3 \%)$.

We found size of calcific deposit and initial VAS has very limited positive correlation $(r=0.313)$. During our study, we observed six (33.3\%) with visible calcific deposit on X-ray were asymptomatic (VAS 0). Two $(11.1 \%)$ had relapsed symptoms though initial improvement hence we labeled them as chronic calcific tendinitis. One patient had right shoulder involved and after three years left shoulder was affected. We saw no case of simultaneous bilateral involvement.

\section{DISCUSSION}

We wanted to make the procedure simple to be done at outpatient clinic, we avoided aspiration as it requires large bore needle eliciting more pain and also requires image guidance. Furthermore, there is insufficient evidence to conclude ultrasound guided needle lavage is superior and needle fenestration may be contributing to observed therapeutic effect. ${ }^{15-17} \mathrm{We}$ also believe needle fenestration may initiate more inflammation to hasten resorptive phase. We used multiple modalities to address the problem as there are many modalities with varying degree of efficacy. ${ }^{1,4}$

Result we obtained may be the summation effect of diclofenac phonophoresis, needle fenestration and 
steroid injection as some reports suggest short term benefit of subacromial steroid and some repost suggest little reproducible benefit. ${ }^{18,19}$ Our aim was not to seek the effectiveness of the individual modality but to address the dramatic painful condition at outpatient clinic and we were able to dramatically end the problem. All our patients were asked to come for initial follow up in one week but some recalled end of pain very next day and some said in few days but all had significant pain relief by one week.

We observed excellent short term relief of pain and regaining of shoulder function but there were two $(11.1 \%)$ recurrence hence we considered those as chronic tendinitis, they reach beneficial plateau within short period hence further improvement in long follow up in not significant which was also reported by Serafini et al, in his series of 10 years of follow up. ${ }^{16}$ Six (33.3\%) with visible calcific deposit on X-ray were completely pain free hence we assume may be calcific deposit itself is not the cause of pain and it can be asymptomatic which is reported in other series too. ${ }^{1,20}$
In our study, we included those who came within one week of symptoms and those who came for follow up for at least one month. Many of our patients did not turn up after the painful episode was over hence we had to exclude them from our study thus decreasing our number of study cases. We may have done longer follow ups to see the long-term behavior of deposit and larger sample size would have been better.

\section{CONCLUSIONS}

Acute calcific tendinitis of shoulder is very painful condition. Diclofenac phonophoresis, needle fenestration and subacromial methyl prednisolone at outpatient clinic gives quick pain relief and improves shoulder function.

Needle fenestration, subacromial steroid and diclofenac phonophoresis without image guidance can be done at simple outpatient clinic with good result.

\section{Conflict of Interest: None.}

\section{REFERENCES}

1. Miller RH III, Azar FM, Throckmorton TW. Shoulder \& Elbow Injuries. In: Azar FM, Beaty JH, Canale ST (eds.) Campbell's Operative Orthopaedics.13th ed. Vol 3. Philadelphia; Elsevier: 2017. p. 2324-5. [Full Text]

2. Loew M, Jurqowski W, Mau HC, Thomsen M. treatment of calcifying tendinitis of rotator cuff by extracorporeal shockwaves: A preliminary report. J Shoulder Elbow Surg.1995;101-6. [PubMed]

3. Riley GP, Harrall RL, Constant CR, Cawston TE, Hazelman BL. Prevalence and possible pathological significance of calcium phosphate salt accumulation in tendon matrix degeneration. Ann Rheum Dis.1996 Feb;55(2):109-15. [PubMed]

4. Depalma AF, Kruper JS. Long term study of shoulder joint afflicted with and treated for calcific tendinitis. Clin orthop. 1961;20:61-72. [PubMed]

5. Rosim GC, Barbieri CH, Lancas FM, Mazzer N. Diclofenac Phonophoresis in human volunteers. Ultrasound Med Biol. 2005 Mar;31(3):337-43. [PubMed | DOI]

6. Oktayoglu P, Gur A, Yardimeden I, Caglayan M, Cevik F, Bozkurt M, et al. comparison of the efficacy of Phonophoresis and Conventional Ultrasound Therapy in Patients with Primary knee osteoarthritis. Erciyes Med J. 2014;36(1):11-8. [DOI $\mid$ Full Text]
7. Deniz S, Topuz O, Atalaya NS, Sarsan A, Yildiz Y, Findikoglu et al. Comparison of effectiveness of pulsed and continuous diclofenac phonophoresis in treatment of knee osteoarthritis. J Phy Ther Sci. 2009;21:331-6.[DOI | Full Text]

8. Anap DB. Khatri S, Prabhakar AJ. Effectiveness of Diclofenac sodium Phonophoresis to resolve pain related to facet syndrome: A case study. J Pharm \& Sci Inov. 2013 Mar-Apr; 2(2):16-20. [DOI | Full Text]

9. Farin PU, Rosanen H, Jaroma H, Harju A. rotator cuff calcifications: treatment with ultrasound-guided percutaneous needle aspiration and lavage. Skeletal Radiol. 1996 Aug;25(6):551-4. [PubMed]

10. Galletti S, Magnani M, Rotini $\mathrm{R}$ et al. The echo-guided treatment of calcific tendinitis of the shoulder. Chir Organi Mov. 2004 Oct-Dec; 89(4):319-23. [PubMed]

11. Gould D, Goldstone K L, Gammon J. Examining the validity of pressure ulcer risk assessment scales: developing and using illustrated patient simulations to collect the data information point: Visual Analogue Scale. J Clin Nurs. 2001 Sep;10(5):697-706. [DOI]

12. Katz J, Melzack R. Measurement of pain. Surg Clin North Am. 1999 Apr;79(2):231-52. [PubMed]

13. Bodian CA, Freedman G, Hossain S et al. The visual analogue scale for pain: clinical significance in postoperative patients. Anesthesiology. 2001 Dec; 95(6):1356-61. [ubMed] 
14. Angst F, Schwyzer HK, Aeschlimann A, Simmen BR, Goldhahn J. Measures of adult shoulder function: disabilities of arm, shoulder, and hand questionnaire (DASH) and its short version (Quick DASH), shoulder pain and disability index (SPADI), American shoulder and elbow surgeon ( ASES )society standardized shoulder assessment form, Constant (Murley) score (CS), simple shoulder test (SST), Oxford shoulder score (OSS), shoulder disability questionnaire ( SDQ ) and western Ontario shoulder instability index (WOSI). Arthritis Care Res (Hoboken). 2011 Nov;63 Suppl 11:S174-88. [PubMed | DOI]

15. Vignesh KN, McdowalL A, Simunovic N, Bhandari M, Choudur HN. Efficacy of ultrasound guided percutaneous needle treatment of calcific tendinitis. AJR Am J Roentgenol. 2015 Jan;204(1):148-52. [PubMed | DOI]
16. Serafini G, Sconfienza LM, Lacelli F, Silvetri E, Aliprandi A, Sardanelli F . Rotator cuff calcific tendonitis: short-term and 10-year outcomes after two-needle US guided percutaneous treatment--nonrandomized control trial. Radiology. 2009 Jul;252(1):157-64. [ubMed | DOI]

17. Chiavaras MM, Jacobson JA. Ultrasound-guided tendon fenestration. Semin Musculoskelet Radiol. 2013 Feb;17(1):85-90. [PubMed | DOI]

18. Arroll B, Goodyear-Smith F. Corticosteroid injection for painful shoulder: a meta-analysis. Br J Gen Prat. 2005 Mar;55(512):224-8. [PubMed]

19. Koester MC, Dunn WR, Kuhn JE, Spindler KP. The efficacy of subacromial corticosteroid injection in the treatment of rotator cuff disease: a systemic review. J Am Acad orthop Surg. 2007 Jan;15(1):3-11. [PubMed]

20. Lam F, Bhatia D, Rooyen KV, Beer JF. Modern Management of calcifying tendinitis of the shoulder. Current Orthopaedics. 2006;20:446-52. [Full Text | DOI] 